\title{
Husband-Wife Correlations in Neurocognitive Test Performance*
}

\author{
C. Thomas Gualtieri \\ North Carolina Neuropsychiatry Clinics, Chapel Hill, USA \\ Email: tg@ncneuropsych.com \\ Received June $20^{\text {th }}, 2013$; revised July $24^{\text {th }}, 2013$; accepted August $26^{\text {th }}, 2013$
}

Copyright $\odot 2013$ C. Thomas Gualtieri. This is an open access article distributed under the Creative Commons Attribution License, which permits unrestricted use, distribution, and reproduction in any medium, provided the original work is properly cited.

\begin{abstract}
Spousal correlations are known to have a number of physical and mental characteristics, among which general mental ability is one of the strongest. IQ tests have ordinarily been used in studies of assortative mating, but in neurocognitive tests, less frequently. In this study, we examined spousal correlations in 76 husband-wife pairs using a computerized neuropsychological test battery. Significant spousal correlations occurred in the two most highly g-loaded tests, shifting attention and symbol digit coding, but not in the other tests or in any of the reaction time measures. The correlation between husbands and wives on the neurocognitive index, a summary score based on the individual tests and analogous to the IQ score, was even higher $(\mathrm{r}=.717)$. The pattern of spousal correlation described in IQ tests is thus replicated in a battery of neuropsychological tests. In a previous paper we reported positive correlations between first-degree relatives who were administered the CNT battery, and which occurred primarily in tests of complex information processing, SDC and SAT (Hervey, Greenfield, \& Gualtieri, 2012). In this paper, we note that the same two tests contribute more strongly than any other tests to the high spousal correlation for neurocognition. There is a certain symmetry, then, between the cognitive skills that play into spouse selection and the cognitive skills that are inherited. A better word than symmetry might be inevitability. The findings of these studies suggest that computerized neurocognitive testing is an appropriate tool for studies of the genetics of cognition, that measures of processing speed are particularly salient and that the CNT is a suitable instrument. The advantages of computerized neurocognitive tests like the CNT include speed and efficiency, standard administration, suitability for repeated measures and elimination of scoring and transcription errors. Tests that are Internet-based like the CNT are amenable to centralized data collection and have flexibility in administration in different settings, even permitting the collection of data from remote sources. In genetic studies of cognition, where large numbers of subjects are necessary, this technology may also be inevitable.
\end{abstract}

Keywords: Computerized Test; Spousal Correlation; Processing Speed; General Mental Ability; Assortative Mating

\section{Introduction}

Mating, among humans and in other species, is not a random event. "Assortative mating" refers to the propensity of males and females to choose mates non-randomly, on the basis of shared or complementary characteristics. In studies of assortative mating, positive correlations between husbands and wives have been discovered in various traits. Among these are physical attributes, like height (Hasstedt, 1995; Courtiol, Raymond, Godelle, \& Ferdy, 2010) and weight (Silventoinen, Kaprio, Lahelma, Viken, \& Rose, 2003); sociodemographic variables like race (Risch et al., 2009) and language preference (Nagoshi, Johnson, \& Danko, 1990); ethnicity (Sebro, Hoffman, Lange, Rogus, \& Risch, 2010), economic status (Torche, 2010) and education (Correia, 2003); and vulnerability to certain pathological conditions (Negri, Melica, Zuliani, \& Smeraldi, 1979; Speakman, Djafarian, Stewart, \& Jackson, 2007; Krueger,

${ }^{*}$ Acknowledgment/Financial Support: Financial support from NC Neuropsychiatry Attention \& Memory Centers. Dr. Gualtieri is the founder/developer of CNS Vital Signs, PA, an older version of the CNT. The CNT is not a commercial property and is available at www.ncneuropsych.com.
Moffitt, Caspi, Bleske, \& Silva, 1998; Norton et al., 2010; Van Grootheest, Van den Berg, Cath, Willemsen, \& Boomsma, 2008; Constantino \& Todd, 2005; Konnov, Dobordzhginidze, Deev, \& Gratsianskiı̌, 2010).

Assortative mating appears to occur for personality traits (Díaz-Morales, Quiroga Estévez, Escribano Barreno, \& Delgado Prieto, 2009; Farley \& Davis, 1977), but to a lesser degree than that observed for physical traits, sociodemographic traits, intelligence, and attitudes and values (Merikangas, 1982; Epstein \& Guttman, 1984).

Spousal correlation or "homogamy" is more evident in studies of cognitive traits than other psychological traits (Zonderman, Vandenberg, Spuhler, \& Fain, 1977; Mascie-Taylor \& Gibson, 1979; Mascie-Taylor, 1989). Considering the various dimensions by which cognition can be measured, the highest spousal correlations are reported for general mental ability, or $g$. $\mathrm{IQ}$, for example, seems to have a higher spousal correlation ( $\mathrm{r}=$ about +.40 ) than any other behavioral trait and is higher than most physical traits (e.g., height, $\mathrm{r}=+.30$ ) (Mascie-Taylor, 1989; Jensen, 1998) (Nagoshi, Johnson, Yuen, \& Ahern, 1986; Nagoshi, Johnson, \& Ahern, 1987). With respect to individual 
tests, for example the subtests of an IQ test battery, Jensen has noted that the correlation for spouses is largely a matter of $g$; that is, the degree to which cognitive tests show assortative mating is highly correlated with the tests' loadings on the $g$ factor.

As cognitive studies rely, with increasing frequency, on computerized test batteries rather than time and labor intensive paper-and-pencil tests, and on neuropsychological tests rather than conventional IQ tests, it is appropriate to explore whether similar patterns emerge when a computerized neurocognitive test battery is applied to areas of investigation that have hitherto been reliant on IQ measures.

\section{Method}

\section{Subjects}

The NCNC database contains the records of $>16,000$ individuals, patients or family members of patients at the North Carolina Neuropsychiatry Clinics in Chapel Hill, Raleigh or Charlotte. Every new patient at the Neuropsychiatry Clinics is administered a computerized neurocognitive test battery; family members are requested to take the test battery as well, in order to better understand the evaluation process. Patients and family members give written informed consent to allow their de-identified data to be used for purposes of research and evaluation; they can take advantage of our website (www.ncneuropsych.com) to withdraw consent at any time.

The database was found to contain the records of 76 husband-wife pairs, parents of children who were referred as patients. All of the parents were in good health. Common conditions like hypertension, obesity, anxiety, depression and ADD were documented in some of the individuals, but none had a disabling medical or neuropsychiatric disorder. The demographic characteristics of the husbands and wives are given in Table 1.

\section{Neurocognitive Evaluation: The CNT battery}

The CNT battery is an updated version of a computerized test battery called CNS Vital Signs, developed by the author (TG) and introduced in 2003 (Gualtieri \& Johnson, 2006). CNS Vital Signs is currently used by clinicians and researchers and has been applied in studies of patients with ADHD (Gualtieri \&

Table 1.

The computerized test battery (CNT).

\begin{tabular}{cccc}
\hline Test & & Time & Factor \\
\hline Verbal Memory & VBM & 3 & Memory \\
Visual Memory & VIM & 3 & Motor speed and \\
Finger Tapping & FTT & 3 & coordination \\
Symbol Digit Coding & SDC & 4 & Central Processing \\
Shifting Attention Test & SAT & 3 & speed \\
Stroop Test & ST & 5 & Effortful attention \\
$\begin{array}{c}\text { Continuous } \\
\text { Performance Test }\end{array}$ & RT & & \\
\hline
\end{tabular}

Johnson, 2008a), traumatic brain injury (Gualtieri \& Johnson, 2008b), dementia (Gualtieri \& Johnson, 2005), mood disorders (Iverson, Brooks, Langenecker, \& Young, 2011) and other clinical conditions (Brooks \& Barlow, 2011). The CNT is identical to the original test battery, save these differences: standardization and scoring have been changed in accord with factor analysis of the tests and controlling for the effects of education; validity measures are incorporated as described in a companion paper; the new test is internet-based; and it is not a commercial product.

The CNT battery contains eight tests that generate nine scores. Seven tests are the topic of this paper; the eighth, keyboard speed, is a new test that is still in development, introduced as an additional validity measure. The seven tests were originally chosen because they were thought to address distinct cognitive domains (Table 2).

The verbal memory (VBM) and visual memory (VIM) tests are adaptations of the Rey Auditory Verbal Learning Test and the Rey Visual Design Learning Test (Rey, 1964; Taylor, 1959). VBM and VIM are tests of recognition memory; they are administered at the beginning and the end of the battery, yielding scores for immediate and delayed memory. The finger tapping test (FTT) is administered in three 10 second segments to each hand. The symbol digit coding test (SDC) is based on the symbol digit modalities test (Smith, 1982). The Stroop Test (ST) has three parts that generate simple and complex reaction times (Stroop, 1935). Averaging the two complex reaction time scores from the Stroop test a "response time" (RT) score. The ST also generates an error score. The Shifting Attention Test (SAT) measures the subject's ability to shift from one instruction set to another quickly and accurately. Other computerized batteries, like the NES2, CogState and CANTAB have shifting attention tests. Color-shape tests like the SAT have also been used in cognitive imaging studies (Le, Pardo, \& Hu, 1998; Nagahama et al., 1998). The SAT score is calculated by subtracting the number of errors from the number of correct responses. The Continuous Performance Test presents 40 targets (the letter "B") embedded among 160 non-target letters over a five minute interval (Rosvold \& Delgado, 1956).

The tests generate raw scores and standard scores. Scores are standardized by adjusting for age and education level. Raw scores were used in these studies.

\section{Data Analysis}

The data being normally distributed, performances of husbands and wives were correlated by Pearson product-moment. Variance was measured by univariate linear regression of wives' scores on husbands' scores.

Table 2.

Characteristics of husbands and wives.

\begin{tabular}{ccccccc}
\hline & \multicolumn{2}{c}{ Husbands } & \multicolumn{2}{c}{ Wives } & \multicolumn{2}{c}{ Pearson's r } \\
\cline { 2 - 7 } & Mean & SD & Mean & SD & r & Sig. \\
\hline $\mathrm{N}$ & 76 & & 76 & & & \\
Age & 47.38 & 11.112 & 46.16 & 10.484 & .813 & .000000 \\
Educ & 16.53 & 2.411 & 16.31 & 1.965 & .564 & .000016 \\
Compfam & 2.65 & .561 & 2.69 & .466 & .063 & .664758 \\
\hline
\end{tabular}




\section{T. GUALTIERI}

\section{Results}

The salient characteristics of the husbands and wives are presented in Table 2. Seventy-four of the couples were both white and two were both African-American. The H-W pairs were highly correlated for age and education level, but not for self-reported computer familiarity.

Significant correlations were found for the cognitive index score, the shifting attention tests and the symbol digit coding test, but not for any of the other tests and not for any of the reaction time measures. $51 \%$ of the variance in spouse A's cognitive index score was attributable to spouse B's score; $25 \%$ in the shifting attention test; and $8 \%$ in the symbol digit coding test (Table 3).

\section{Discussion}

Homogamy, or assortative mating (AM), is one of the ways Nature makes mate selection systematic. It is a fact of life not only for the animals but also in every human society. The large majority of mates resemble each other in a high number of traits: age, race, religion, ethnicity, social class, economic status, intellectual ability, education, personality traits, values and opinions, physical attractiveness, hobbies, previous marital status, occupation and various anthropometric measures, like height, weight and eye color and hair color. Spousal correlation is more evident in studies of cognition than physical characteristics or other psychological traits (Zonderman et al., 1977; Mascie-Taylor \& Gibson, 1979; Mascie-Taylor, 1989; MascieTaylor, 1989; Mascie-Taylor, 1989).

Why does it happen? We don't really know. There are theories, of course: the Genetic Similarity Theory, that we are able to detect genetically similar organisms - from how they look and how they behave - and "channel our altruistic behavior towards them" (Rushton, 1989). That means that we prefer to invest in someone else's genes if we happen to have the same genes. Then, there is the Sexual Imprinting Theory, that we select mates who resemble our counter-sexual parent (Bereczkei, Gyuris, \& Weisfeld, 2004). This happens even when we don't share their genes: adopted children, for example, prefer mates who resemble their counter-sexual adoptive parent. Then there is the simple argument that AM works. A certain degree of similarity between mates is said to enhance marital stability

Table 3.

Spousal correlations for the tests.

\begin{tabular}{cccc}
\hline & \multicolumn{2}{c}{ Pearson's $\mathrm{r}$} & \multicolumn{2}{c}{ Lin reg } \\
\cline { 2 - 4 } & $\mathrm{r}$ & Sig. & $\mathrm{r}^{2}$ \\
\hline Index Score & .717 & .000 & .514 \\
Shifting Attention Test & .496 & .000 & .246 \\
Symbol Digit Coding & .284 & .013 & .081 \\
Verbal Memory & .157 & .175 & .025 \\
Visual Memory & .145 & .213 & .021 \\
Finger Tapping Test & .076 & .515 & .006 \\
Continuous Performance Test & .050 & .676 & .003 \\
Stroop Errors & -.048 & .68 & .002 \\
Stroop Response Time & -.030 & .797 & .001 \\
\hline
\end{tabular}

and fertility (Bereczkei \& Csanaky, 1996; Bentler \& Newcomb, 1978; Mascie-Taylor, 1989; Lucas et al., 2004; Wilson \& Cousins, 2003). Homogamy is the way that Nature preserves the stability of a species. It is also a way for new species to form, as organisms mate homogamously around some new and interesting mutation until they form an entirely new species.

Studies have consistently indicated that homogamy for mental ability reflects initial assortment (i.e., similarity at the time of marriage) rather than convergence (i.e., increasing similarity with time) (Watson et al., 2004; Zonderman et al., 1977). Numerous studies from 1926 through 1979 have indicated spousal correlations for intelligence ranging from .12 to .76, with a weighted mean correlation of .44 (Johnson, Ahern, \& Cole, 1980). With respect to individual tests, for example the subtests of an IQ test battery, it has been noted that the correlation for spouses is largely a matter of $g$; that is, the degree to which cognitive tests show assortative mating is highly correlated with the tests' loadings on the $g$ factor (Jensen, 1998). In this study, a summary score based on the individual neurocognitive tests and analogous to an IQ score, demonstrated a much higher spousal correlation than any of the tests by themselves. Among the individual tests, shifting attention and symbol digit coding were significantly correlated; but none of the other tests were, nor were any of the reaction time measures.

The shifting attention and coding tests on the CNT load together as a single measure of the speed and efficiency of information processing, which is recognized to be a highly $g$ loaded factor (Jensen, 1998). Studies in our clinics of 179 adults who were tested with the Wechsler scales and the CNT battery indicated a positive correlation between full scale IQ and the symbol digit coding test $(r=.465, P<.01)$ and with the shifting attention test $(\mathrm{r}=.59, P<.01)$ (Gualtieri, CT \& Hervey, AS, 2013).

Recent studies have been more interested in specific tests than measures of general mental ability. In two studies, one of 318 spouse pairs and one of 123 , significant positive spousal correlations were observed for almost all cognitive variables except attention and psychomotor speed (Dufouil \& Alpérovitch, 2000; Zonderman et al., 1977). In our study, in contrast, we found a clear differentiation between tests of processing speed and other neuropsychological tests. Perhaps that is a function of the smaller number of spouse pairs, or possibly the fact that the parents in this sample have children with neuropsychiatric disorders. On the other hand, large N's may artificially inflate the number of variables that are statistically significant. An $\mathrm{r}$ of .18 may be significant in a study of 123 subjects, but will only account for about $3 \%$ of variance attributable to that factor. And, if anything, the presence of illness in one spouse or another, or in the offspring, might work against the hypothesis of positive spousal correlation. The small number of husband-wife pairs in this study is a problem; the fact that our results are in accord with previous studies is re-assuring.

In a previous paper we reported positive correlations between first-degree relatives who were administered the CNT battery, and which occurred primarily in tests of complex information processing, SDC and SAT (Hervey, Greenfield, \& Gualtieri, 2012). In this paper, we note that the same two tests contribute more strongly than any other tests to the high spousal correlation for neurocognition. There is a certain symmetry, then, between the cognitive skills that play into spouse selection and the cognitive skills that are inherited. A better word than sym- 


\section{T. GUALTIERI}

metry might be inevitability.

The findings of these studies suggest that computerized neurocognitive testing is an appropriate tool for studies of the genetics of cognition, that measures of processing speed are particularly salient and that the CNT is a suitable instrument. The advantages of computerized neurocognitive tests like the CNT include speed and efficiency, standard administration, suitability for repeated measures and elimination of scoring and transcription errors. Tests that are Internet-based like the CNT are amenable to centralized data collection and have flexibility in administration in different settings, even permitting the collection of data from remote sources. In genetic studies of cognition, where large numbers of subjects are necessary this technology may also be inevitable.

\section{REFERENCES}

Rey, A. (1964). L'examen clinique en psychologie. Paris: Presses Universitaires de France.

Bentler, P. M., \& Newcomb, M. D. (1978). Longitudinal study of marital success and failure. Journal of Consulting and Clinical Psychology, 46, 1053-1070. http://dx.doi.org/10.1037/0022-006X.46.5.1053

Bereczkei, T., \& Csanaky, A. (1996). Mate choice, marital success, and reproduction in a modern society. Ethology and Sociobiology, 17, 17-35. http://dx.doi.org/10.1016/0162-3095(95)00104-2

Bereczkei, T., Gyuris, P., \& Weisfeld, G. E. (2004). Sexual imprinting in human mate choice. Proceedings of the Royal Society of London. Series B: Biological Sciences, 271, 1129-1134. http://dx.doi.org/10.1098/rspb.2003.2672

Brooks, B. L., \& Barlow, K. M. (2011). A methodology for assessing treatment response in Hashimoto's encephalopathy: A case study demonstrating repeated computerized neuropsychological testing. Journal of child neurology, 26, 786-791.

http://dx.doi.org/10.1177/0883073810391532

Constantino, J. N., \& Todd, R. D. (2005). Intergenerational transmission of subthreshold autistic traits in the general population. Biological Psychiatry, 57, 655-660.

http://dx.doi.org/10.1016/j.biopsych.2004.12.014

Correia, H. R. (2003). Higher male educational hypergamy: Evidence from Portugal. Journal of Biosocial Science, 35, 303-313. http://dx.doi.org/10.1017/S0021932003003031

Courtiol, A., Raymond, M., Godelle, B., \& Ferdy, J.-B. (2010). Mate choice and human stature: Homogamy as a unified framework for understanding mating preferences. Evolution: International Journal of Organic Evolution, 64, 2189-2203. http://dx.doi.org/10.1111/j.1558-5646.2010.00985.x

Díaz-Morales, J. F., Quiroga Estévez, M. A., Escribano Barreno, C., \& Delgado Prieto, P. (2009). Assortative mating in temperament and intelligence, and the role of marital satisfaction. Psicothema, 21, 262267.

Dufouil, C., \& Alpérovitch, A. (2000). Couple similarities for cognitive functions and psychological health. Journal of Clinical Epidemiology, 53, 589-593. http://dx.doi.org/10.1016/S0895-4356(99)00189-4

Epstein, E., \& Guttman, R. (1984). Mate selection in man: Evidence, theory, and outcome. Social Biology, 31, 243-278.

Farley, F. H., \& Davis, S. A. (1977). Arousal, personality, and assortative mating in marriage. Journal of Sex \& Marital Therapy, 3, 122127. http://dx.doi.org/10.1080/00926237708402977

Gualtieri, C., \& Johnson, L. (2005). Neurocognitive testing supports a broader concept of mild cognitive impairment. American Journal of Alzheimer's Disease and Other Dementias, 20, 359-366. http://dx.doi.org/10.1177/153331750502000607

Gualtieri, C., \& Johnson, L. (2006). Reliability and validity of a computerized neurocognitive test battery, CNS Vital Signs. Archives of Clinical Neuropsychology: The Official Journal of the National Academy of Neuropsychologists, 21, 623-643. http://dx.doi.org/10.1016/j.acn.2006.05.007
Gualtieri, C., \& Johnson, L. (2008a). Medications do not necessarily normalize cognition in ADHD patients. Journal of Attention Disorders, 11, 459-469. http://dx.doi.org/10.1177/1087054707305314

Gualtieri, C., \& Johnson, L. (2008b). A computerized test battery sensitive to mild and severe brain injury. Medscape Journal of Medicine, $10,90$.

Gualtieri, C. T., \& Hervey, A. S. (2013). The structure and meaning of a computerized neurocognitive test. Ms Submitted.

Hasstedt, S. J. (1995). Phenotypic assortative mating in segregation analysis. Genetic Epidemiology, 12, 109-127. http://dx.doi.org/10.1002/gepi.1370120202

Hervey, A. S., Greenfield, K., \& Gualtieri, C. T. (2012). Heritability in cognitive performance: Evidence using computer-based testing. The Journal of Genetic Psychology, 173, 112-118. http://dx.doi.org/10.1080/00221325.2011.573025

Iverson, G. L., Brooks, B. L., Langenecker, S. A., \& Young, A. H. (2011). Identifying a cognitive impairment subgroup in adults with mood disorders. Journal of Affective Disorders, 132, 360-367. http://dx.doi.org/10.1016/j.jad.2011.03.001

Jensen, A. R. (1998). The heritability of g. In The g factor: The science of mental ability (pp. 169-203). London: Praeger.

Johnson, R. C., Ahern, F. M., \& Cole, R. E. (1980). Secular change in degree of assortative mating for ability? Behavior Genetics, 10, 1-8. http://dx.doi.org/10.1007/BF01067315

Konnov, M. V., Dobordzhginidze, L. M., Deev, A. D., \& Gratsianskiir, N. A. (2010). Spousal concordance for factors related to metabolic syndrome in families of patients with premature coronary heart disease. Kardiologiia, 50, 4-8.

Krueger, R. F., Moffitt, T. E., Caspi, A., Bleske, A., \& Silva, P. A. (1998). Assortative mating for antisocial behavior: Developmental and methodological implications. Behavior Genetics, 28, 173-186. http://dx.doi.org/10.1023/A:1021419013124

Le, T. H., Pardo, J. V., \& Hu, X. (1998). 4 T-fMRI study of nonspatial shifting of selective attention: cerebellar and parietal contributions. Journal of Neurophysiology, 79, 1535-1548.

Lucas, T. W., Wendorf, C. A., Imamoglu, E. O., Shen, J., Parkhill, M. R., Weisfeld, C. C., \& Weisfeld, G. E. (2004). Marital satisfaction in four cultures as a function of homogamy, male dominance and female attractiveness. Sexualities, Evolution \& Gender, 6, 97-130. http://dx.doi.org/10.1080/14616660412331327518

Mascie-Taylor, C. G. (1989). Spouse similarity for IQ and personality and convergence. Behavior Genetics, 19, 223-227. http://dx.doi.org/10.1007/BF01065906

Mascie-Taylor, C. G., \& Gibson, J. B. (1979). A biological survey of a Cambridge suburb: Assortative marriage for IQ and personality traits. Annals of Human Biology, 6, 1-16. http://dx.doi.org/10.1080/03014467900003321

Merikangas, K. R. (1982). Assortative mating for psychiatric disorders and psychological traits. Archives of General Psychiatry, 39, 11731180. http://dx.doi.org/10.1001/archpsyc.1982.04290100043007

Nagahama, Y., Sadato, N., Yamauchi, H., Katsumi, Y., Hayashi, T., Fukuyama, H., et al. (1998). Neural activity during attention shifts between object features. Neuroreport, 9, 2633-2638. http://dx.doi.org/10.1097/00001756-199808030-00038

Nagoshi, C. T., Johnson, R. C., \& Ahern, F. M. (1987). Phenotypic assortative mating vs. social homogamy among Japanese and Chinese parents in the Hawaii Family Study of Cognition. Behavior Genetics, 17, 477-485. http://dx.doi.org/10.1007/BF01073114

Nagoshi, C. T., Johnson, R. C., \& Danko, G. P. (1990). Assortative mating for cultural identification as indicated by language use. Behavior Genetics, 20, 23-31. http://dx.doi.org/10.1007/BF01070737

Nagoshi, C. T., Johnson, R. C., Yuen, S. H., \& Ahern, F. M. (1986). Further investigations of educational and occupational attainment in the Hawaii Family Study of Cognition. Social Biology, 33, 35-50.

Negri, F., Melica, A. M., Zuliani, R., \& Smeraldi, E. (1979). Assortative mating and affective disorders. Journal of Affective Disorders, 1, 247-253. http://dx.doi.org/10.1016/0165-0327(79)90011-9

Norton, M. C., Smith, K. R., Østbye, T., Tschanz, J. T., Corcoran, C., Schwartz, S., et al. (2010). Greater risk of dementia when spouse has dementia? The Cache County study. Journal of the American Geriatrics Society, 58, 895-900. 


\section{T. GUALTIERI}

http://dx.doi.org/10.1111/j.1532-5415.2010.02806.x

Risch, N., Choudhry, S., Via, M., Basu, A., Sebro, R., Eng, C., et al. (2009). Ancestry-related assortative mating in Latino populations. Genome Biology, 10, R132.

http://dx.doi.org/10.1186/gb-2009-10-11-r132

Rosvold, H. E., \& Delgado, J. M. (1956). The effect on delayed-alternation test performance of stimulating or destroying electrically structures within the frontal lobes of the monkey's brain. Journal of Comparative and Physiological Psychology, 49, 365-372. http://dx.doi.org/10.1037/h0087991

Rushton, J. P. (1989). Genetic similarity, human altruism, and group selection. Behavioral and Brain Sciences, 12, 503-559. http://dx.doi.org/10.1017/S0140525X00057320

Sebro, R., Hoffman, T. J., Lange, C., Rogus, J. J., \& Risch, N. J. (2010). Testing for non-random mating: Evidence for ancestry-related assortative mating in the Framingham heart study. Genetic Epidemiology, 34, 674-679. http://dx.doi.org/10.1002/gepi.20528

Silventoinen, K., Kaprio, J., Lahelma, E., Viken, R. J., \& Rose, R. J. (2003). Assortative mating by body height and BMI: Finnish twins and their spouses. American Journal of Human Biology: The Official Journal of the Human Biology Council, 15, 620-627.

http://dx.doi.org/10.1002/ajhb.10183

Smith, A. (1982). Symbol Digit Modalities Test (SDMT). Manual (Revised). Los Angeles: Western Psychological Services.

Speakman, J. R., Djafarian, K., Stewart, J., \& Jackson, D. M. (2007). Assortative mating for obesity. The American Journal of Clinical
Nutrition, 86, 316-323.

Stroop, J. (1935). Studies of interference in serial verbal reactions. Journal of Experimental Psychology, 18, 643-662.

http://dx.doi.org/10.1037/h0054651

Taylor, E. M. (1959). The appraisal of children with cerebral deficits. Cambridge, MA: Harvard University Press.

Torche, F. (2010). Educational assortative mating and economic inequality: A comparative analysis of three Latin American countries. Demography, 47, 481-502. http://dx.doi.org/10.1353/dem.0.0109

Van Grootheest, D. S., Van den Berg, S. M., Cath, D. C., Willemsen, G., \& Boomsma, D. I. (2008). Marital resemblance for obsessivecompulsive, anxious and depressive symptoms in a population-based sample. Psychological Medicine, 38, 1731-1740. http://dx.doi.org/10.1017/S0033291708003024

Watson, D., Klohnen, E. C., Casillas, A., Simms, E. N., Haig, J., \& Berry, D. S. (2004). Match makers and deal breakers: Analyses of assortative mating in newlywed couples. Journal of Personality, 72, 1029-1068. http://dx.doi.org/10.1111/j.0022-3506.2004.00289.x

Wilson, G., \& Cousins, J. (2003). Partner similarity and relationship satisfaction: Development of a compatibility quotient. Sexual and Relationship Therapy, 18, 161-170.

http://dx.doi.org/10.1080/1468199031000099424

Zonderman, A. B., Vandenberg, S. G., Spuhler, K. P., \& Fain, P. R. (1977). Assortative marriage for cognitive abilities. Behavior Genetics, 7, 261-271. http://dx.doi.org/10.1007/BF01066279 